\title{
A comparison of two reciprocating instruments using bending stress and cyclic fatigue tests
}

\section{Pantaleo SCELZA ${ }^{(a)}$ \\ Harry DAVIDOWICZ(b) \\ Licinio Esmeraldo da SILVA ${ }^{(c)}$ \\ Igor Bastos BARBOSA(a) \\ Miriam Zaccaro SCELZA ${ }^{(a)}$}

(a) Universidade Federal Fluminense - UFF, School of Dentistry, Department of

Endodontics, Niterói, RJ, Brazil.

(b) Centro de Estudos Treinamento e Aperfeiçoamento em Odontologia - CETAO, São Paulo, SP, Brazil.

(c) Universidade Federal Fluminense - UFF, School of Mathematics, Department of Statistics, Niterói, RJ, Brazil.

Declaration of Interests: The authors certify that they have no commercial or associative interest that represents a conflict of interest in connection with the manuscript.

Corresponding Author:

Miriam Zaccaro Scelza

E-mail: scelza@terra.com.br

DOI: 10.1590/1807-3107BOR-2015.vol29.0107

Submitted: Apr 18, 2015

Accepted for publication: Aug 09, 2015

Last revision: Aug 31, 2015
Abstract: The aim of this study was to comparatively evaluate the bending resistance at $45^{\circ}$, the static and dynamic cyclic fatigue life, and the fracture type of the WaveOne (Dentsply Maillefer, Ballaigues, Switzerland) 25-08 and Reciproc (VDW, Munich, Germany) 25-08 instruments. A total of 60 nickel-titanium (NiTi) instruments (30 Reciproc and 30 WaveOne) from three different lots, each of which was $25 \mathrm{~mm}$ in length, were tested. The bending resistance was evaluated through the results of a cantilever-bending test conducted using a universal testing machine. Static and dynamic cyclic fatigue testing was conducted using a custom-made device. For the static and dynamic tests, a cast Ni-Cr-Mo-Ti alloy metal block with an artificial canal measuring $1.77 \mathrm{~mm}$ in diameter and $20.00 \mathrm{~mm}$ in total length was used. A scanning electron microscope was used to determine the type of fracture. Statistical analyses were performed on the results. The WaveOne instrument was less flexible than the Reciproc $(\mathrm{p}<0.05)$. The Reciproc instrument showed better resistance in the static and dynamic cyclic fatigue tests $(p<0.05)$. The transverse cross-section and geometry of the instruments were important factors in their resistance to bending and cyclic fracture. Both of the instruments showed ductile-type fracture characteristics. It can be concluded that the Reciproc 25-08 instrument was more resistant to static and dynamic cyclic fatigue than the WaveOne 25-08 instrument, while the WaveOne 25-08 instrument was less flexible. Bending and resistance to cyclic fracture were influenced by the instruments' geometries and transverse cross-sections. Both of the instruments showed ductile-type fracture characteristics.

Keywords: Dental Instruments; Endodontics; Stress, Mechanical.

\section{Introduction}

Due to their flexibility and elasticity, nickel-titanium (NiTi) instruments have been introduced into the endodontic arsenal to facilitate the instrumentation of curved canals. ${ }^{1,2,3}$ However, their flexibility does not guarantee elimination of the risk of fracture in severely curved root canals. ${ }^{4,5}$

Fractures of NiTi instruments in rotary motion may be caused by cyclic bending fatigue due to the tensile stress and compression induced in the instrument or by twisting, which occurs when the instrument continues 
to spin when its tip is immobilized. These events can occur separately or simultaneously.,

Reciprocating instruments have been developed to reduce the stress that rotary instruments suffer, particularly during the preparation of curved canals. ${ }^{7}$

Reciprocating motion is an oscillating motion that occurs when an instrument rotates in one direction and reverses its direction before completing a full rotary cycle. ${ }^{8}$ The use of reciprocating motion can extend the lifespan of a NiTi instrument and allow it to resist fatigue better than it can with continuous rotation., ${ }^{9} 10$

The literature has shown that the Reciproc and WaveOne reciprocating instruments have different rotation angles and speeds. The Reciproc instrument is able to rotate $150^{\circ}$ counterclockwise and $30^{\circ}$ clockwise at a speed of $300 \mathrm{rpm}$, and the WaveOne instrument rotates $170^{\circ}$ counterclockwise and $50^{\circ}$ clockwise at a speed of $350 \mathrm{rpm} .^{11}$

The aim of this study was to perform a comparative evaluation of the bending resistance at $45^{\circ}$, the static and dynamic cyclic fatigue life, and the type of fracture encountered with the Reciproc 25-08 and the WaveOne 25-08 instruments.

\section{Methodology}

A total of 60 NiTi reciprocating instruments, 30 Reciproc (VDW, Munich, Germany) and 30 WaveOne (Dentsply Maillefer, Ballaigues, Switzerland), from three different lots, each with a nominal size of $0.25 \mathrm{~mm}$ at $\mathrm{D}_{0}$ and a length of $25 \mathrm{~mm}$, were selected. To ensure experimental standardization and reliability, the instruments tested were examined for defects or deformities under a stereomicroscope (Mitutoyo Model MSM-412; Mitutoyo Sul Americana, Suzano, Brazil).

\section{The Bending Resistance Test}

The bending resistance was evaluated using a cantilever-bending test conducted using a system consisting of a bench drill with a tapered mandrel (the mandrel was $1 / 2 \times 20$ UNF, R. Bosch, Campinas, Brazil) that was held by a wooden jig bolted to the traction machine table. The mandrel had a negative slope of $45^{\circ}$ relative to the axis parallel to the table. Ten (10) instruments of each type were tested using a universal testing machine (Máquina de Ensaio Mecânico Universal Kratos; Kratos Equipamentos Industriais Ltda., Cotia, Brazil. Model: K
500SMP). The instruments were attached to the mandrel with their cables. The test speed was $15 \mathrm{~mm} / \mathrm{min}$, and the load cell used was $100 \mathrm{kgf}$. One end of a flexible stainless steel wire that was $50 \mathrm{~cm}$ long and $0.34 \mathrm{~mm}$ in diameter was fastened to the testing machine's head, and the other end was positioned $3 \mathrm{~mm}$ away from the instrument tip until it displayed a $45^{\circ}$ deflection (Figure 1)..$^{12}$ The maximum load needed to bend each file was recorded and statistically analyzed.

\section{The Cyclic Fatigue Test}

Cyclic fatigue was tested using a custom-made machine consisting of a metallic base, column, and bench drill workbench (Figure 2). A pneumatic cylinder (Linear Guide cylinder, Belair Pneumatics Ltd., Novo Hamburgo, Brazil) was fitted to the column to be used for the vertical movements of the handpiece along with a device capable of stabilizing the handpiece. The equipment allowed a small change (set) the ascent rate and cylinder descent, time and cylinder actuation force by pneumatic valves (Directional Valve Series 7000, 1/4, Belair Pneumatics Ltd., Novo Hamburgo, Brazil). To stabilize the simulated canal, we used a vise for the bench drill (No. 01- MF100; Motomil Ind. e Com., Navegantes, Brazil).

For the test, a cast metallic alloy block made of Ni-CrMo-Ti (76\% Ni, $13.5 \%$ Cr, 6\% Mo, 4\% Ti) (Talladium Inc., Valencia, USA) with a Vickers hardness of $452 \mathrm{kgf} / \mathrm{mm}^{2}$ was used. An artificial canal with an inner diameter of $1.77 \mathrm{~mm}$, a total length of $20.0 \mathrm{~mm}$, and arcs with a radius of curvature of $6.0 \mathrm{~mm}$ on the tips was molded

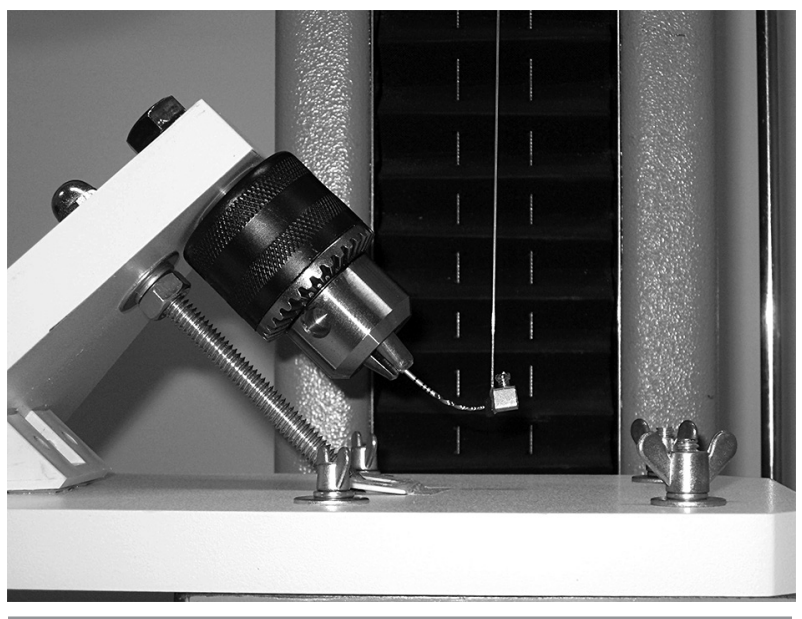

Figure 1. The $45^{\circ}$ bending test apparatus. 


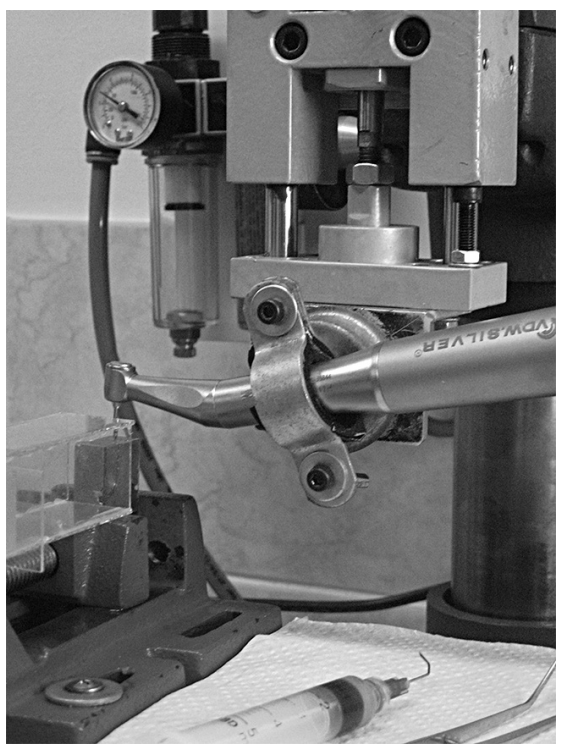

Figure 2. The Cyclic fracture test machine.

for casting. The arc measured $9.4 \mathrm{~mm}$, and the straight portion measured $10.6 \mathrm{~mm}$. After casting, the block was polished, and a glass slide was attached to view the fracture.

\section{The Static Test}

Ten of each reciprocating instrument were activated following the manufacturers' instructions using a 6:1 reduction handpiece (Sirona Dental Systems GmbH, Bensheim, Germany) powered by a torque-controlled motor (Silver Reciproc; VDW, Munich, Germany) and using the pre-set programs for each one (Reciproc ALL - 300 rpm and WaveOne ALL - 350 rpm).

The instruments rotated freely within a metal block filled with mineral oil (Óleo Singer Lubrificante Multiuso; Singer do Brasil Ind. e Com. Ltda., Indaiatuba, Brazil) to reduce friction and heat production. Each instrument was positioned in a contra-angle handpiece and introduced into the canal until its tip touched a shield positioned at the other extremity. This shield was subsequently removed because it was only used to standardize the instrument's penetration into the canal. The time was recorded and stopped as soon as a fracture was detected visually and/or audibly. The number of cycles to fracture (NCF) was recorded. The NCF corresponded to the product of the time until a fracture (in seconds) and the number of revolutions per second. Time was measured using a digital chronometer (Vollo VL-501 Digital Chronometer; Cotia, Brazil). The fragments obtained after fracture were separated and kept for analysis using a scanning electron microscope (SEM; JSM-6510 LV; JEOL, Tokyo, Japan).

\section{The Dynamic Test}

Ten of each reciprocating instrument were tested. The procedures were similar to those of the static test except that there was vertical motion with an amplitude of $3 \mathrm{~mm}$ with pauses after every $3 \mathrm{sec}$ of oscillations while the instrument performed its reciprocating motion. A glass box was used to increase operator safety by containing the fractured fragments.

\section{Results}

\section{The $45^{\circ}$ Flex Test}

In the bending test, which used a cantilever beam situation with a slope of $-45^{\circ}$ (from a Cartesian axis), the WaveOne 25-08 instrument's bending resistance at $45^{\circ}$ was superior to that of the Reciproc 25-08 instrument. Student's $t$ test (at a significance level of a $=0.05$ ) found a statistically significant difference $(p<0.05)$ between the forces applied to the instruments. Table 1 shows the force in $\mathrm{N}$ that resulted in bending at $45^{\circ}$.

\section{The Static Cyclic Fracture Test}

The Reciproc instrument had a greater NCF than the WaveOne instrument in the static cyclic fracture test. Student's $\mathrm{t}$ test found a statistically significant difference in the NCFs of the Reciproc and WaveOne instruments $(p<0.05)$. Table 2 statistically describes the NCFs of the instruments tested in each group.

\section{The Dynamic Cyclic Fracture Test}

The Reciproc instrument had a greater NCF than the WaveOne instrument in the cyclic dynamic fracture test. Student's $t$ test found a statistically significant difference between the NCFs of the Reciproc and WaveOne instruments $(p<0.05)$. Table 3 shows the NCFs of the instruments in each group.

In the $45^{\circ}$ bending test, the WaveOne instrument's bending resistance was greater than the Reciproc's.

For cyclic fractures in the static and dynamic situations, it was observed that the NCF measured for the Reciproc instrument was larger than that measured for the WaveOne instrument. 
Table 1. the mean bending resistance of the instruments tested at $45^{\circ}$.

\begin{tabular}{lccccccc}
\hline Instrument 25-08 & $\mathrm{n}$ & Mean & $\mathrm{SD}$ & Minimum & Maximum & MEDIAN & IQR \\
\hline WaveOne & 10 & 4.879 & 0.5971 & 3.972 & 5.835 & 4.9765 & 0.981 \\
Reciproc & 10 & 4.163 & 0.5454 & 3.236 & 5.149 & 4.1435 & 0.588 \\
\hline
\end{tabular}

SD: standard deviation, IQR: interquartile range, both measured as force $(N)$.

Table 2. Statistical descriptions of the NCFs observed for the instruments in the static test groups.

\begin{tabular}{lccccccc}
\hline Instrument 25-08 & $\mathrm{n}$ & Mean & SD & Minimum & Maximum & MEDIAN & IQR \\
\hline Reciproc & 10 & 2384.5 & 258.16 & 2010 & 2935 & 2375 & 180 \\
WaveOne & 10 & 870.6 & 308.52 & 458.2 & 1461.6 & 846.8 & 516.2 \\
\hline
\end{tabular}

SD: standard deviation, IQR: interquartile range.

Table 3. Statistical descriptions of the NCFs observed for the instruments in the dynamic test groups.

\begin{tabular}{lccccccc}
\hline Instruments 25-08 & $\mathrm{n}$ & Mean & $\mathrm{SD}\left({ }^{*}\right)$ & Minimum & Maximum & MEDIAN & IQR \\
\hline Reciproc & 10 & 2247.5 & 400.61 & 1650 & 2615 & 2302.5 & 555 \\
WaveOne & 10 & 996.6 & 146.70 & 806.2 & 1194.8 & 965.7 & 237.8 \\
\hline
\end{tabular}

SD standard deviation, IQR interquartile range.

An analysis using electron microscopy revealed that under both static and dynamic conditions, the instruments' fracture surfaces had microstructures in which where a substantial number of ripples (i.e., "dimples") could be observed, suggesting ductile fractures.

\section{Discussion}

This study compared the $45^{\circ}$ bending and the static and dynamic cyclic fatigue resistances of two M-wire NiTi reciprocating endodontic instruments that were selected because of their similar in sizes and manufacturing processes. Reciprocating motion was developed to overcome the influence of canal curvature. With this type of motion, the instrument engages dentin at its tip during its counterclockwise movement, and the clockwise movement disengages the instrument immediately afterwards, reducing the torsional stress due to taper locking. ${ }^{13}$

Although they were manufactured using the same alloy, the tested instruments differed in the shapes and areas of their cross-sections. WaveOne instruments have modified concave triangular cross-sections at the tip and convex triangular cross-sections in the middle, and the coronal portions of the instrument have cross-sections that are similar to those of the ProTaper (Dentsply Maillefer, Ballaigues, Switzerland). ${ }^{14,15,16}$
Reciproc instruments have S-shaped cross-sections with two cutting blades that are similar to the cross-section of the Mtwo (VDW). ${ }^{17,18}$

The Reciproc instrument tapers $8 \%$ from $D_{1}$ to $D_{3}$ and $3 \%$ from $\mathrm{D}_{4}$ to $\mathrm{D}_{16}$, and the WaveOne instrument tapers $8 \%$ from $D_{1}$ to $D_{3}$. From $D_{4}$ to $D_{16}$, the WaveOne has a unique design that tapers at a progressively decreasing percentage, i.e., $6.5 \%$ at $\mathrm{D}_{4}, 6 \%$ from $\mathrm{D}_{5}$ to $\mathrm{D}_{15}$, and $5.5 \%$ at $\mathrm{D}_{16}{ }^{19}$

The results obtained in this study indicated that the WaveOne instrument had a greater bending resistance than the Reciproc instrument. However, the Reciproc instrument's performance was superior to the WaveOne instrument's in both the static and dynamic cyclic fracture tests. These findings are similar to those of other authors who analyzed the instruments used in this study with the same or different tip diameters. ${ }^{11,18,20}$

As Zhang et al. ${ }^{21}$ reported, different cross-sectional shapes can lead to changes in both the instruments' mechanical behavior and their design. Faced with such a statement and knowing how the cross-section varied, it was possible to infer based information derived from the resistances of the materials used that the larger the area of the cross-sectional straight section, the less flexible the instrument, and consequently, the larger its resistance 
to bending and stiffness, which could adversely affect its resistance to static and dynamic cyclic fracture. ${ }^{22}$ Starting from this assumption, we sought to confirm this assertion through bench testing.

The literature presents a variety of methods and equipment used to study the mechanical behavior of NiTi instruments. However, there is no specification or international standard test suitable for the evaluation of rotary, reciprocating, or oscillatory NiTi instruments. Most of the models studied in bench testing, excluding, in this context, numerical models such as finite element analysis, are derivations from or adaptations of the tests defined by the ANSI/ADA $n^{\circ} .28$ and ISO 3630/1 specifications that evaluate the resistance to torsion and the flexibility of manual stainless steel files with ISO.02 tapers. Similarly, the ranges of simulated canals with different angles and radii of curvature are large, as is the range of materials examined, which vary from acrylic resin blocks to metal tubes and conformations of canal models using electroerosion. ${ }^{23,24,25}$

In this study, a battery of tests was performed to measure flexibility to $45^{\circ}$. In the traction machine, the vertical displacement of the instrument was $15.55 \mathrm{~mm}$, a value obtained using trigonometry $\left(\sin 45^{\circ}\right)$.

The recorded values were subjected to a statistical analysis, which indicated that the WaveOne instrument had a greater bending resistance than the Reciproc instrument - a $17.19 \%$ difference. Therefore, the WaveOne instrument was less flexible than the Reciproc instrument. This finding may explain why the cross-sectional area and the instrument core had visible effects on the final results, indicating that the Reciproc instrument had the best bending resistance; the WaveOne instrument, in the region of $\mathrm{D}_{4 \cdot 70}$ alone, had an area that was $17.09 \%$ larger than the corresponding area in the Reciproc instrument. Extrapolating these results to other diameters because the WaveOne instrument was more tapered, there appeared to be a very significant increase in the cross-sectional area as the diameter increased. Therefore, it can be inferred that there is a proportional relationship between increases in the area and core diameter and the reduction in flexibility.

Static and dynamic cyclic fracture tests were performed with simulated curved canals. Although they did not reflect clinical reality, these tests allowed the performance of the instruments to be observed. However, it should be noted that in the static situation, a single point along the curvature generated the stress, whereas in the dynamic test, the stress was distributed over $3 \mathrm{~mm}$ of the instrument and occurred during its vertical motion.

However, the higher flexibility and, probably, the lower tapering of the Reciproc instrument after $D_{3}$ meant that its performance in the static and dynamic cyclic fracture tests yielded better results than those of the WaveOne instrument.

Even though they are considered "one-way instruments," it was clear that the Reciproc instrument was capable of supporting a larger NCF than the WaveOne instrument. In the cyclic static fracture test, the NCF of the Reciproc instrument averaged $173.89 \%$ above that of the WaveOne instrument; for the dynamic test, the figure was $125.51 \%$. These results confirm those reported by De-Deus et al., ${ }^{20}$ who evaluated the same instruments with a different tip diameter than the one used in the present study.

By converting the number of cycles until failure to a lifetime in minutes, one can say that on average, taking into account the static fracture, the Reciproc instrument has a lifespan of $8.34 \mathrm{~min}$, and the WaveOne instrument has a lifespan of 2.48 minutes. For dynamic fracture, the Reciproc instrument has a lifespan of $7.49 \mathrm{~min}$, and the WaveOne instrument has a lifespan of 3.24 minutes.

Bahia et al. ${ }^{26}$ noted that in situations calling for curved canal instrumentation, a factor to be considered in the superelastic behavior of NiTi alloys is the extent of cyclic deformation. Under these conditions, such deformation should be no more than $5 \%$. The authors deduced from geometric models that the extent of deformation, $\varepsilon$, is $\varepsilon=(2 \mathrm{r} / \mathrm{d}-1)^{-1}$, where $\mathrm{r}$ is the canal's radius of curvature measured at the outer part of the curve and $d$ is the diameter of the instrument at the midpoint of the curve. These authors designed canals such that the maximum strain amplitude was related to the midpoints of their curved segments.

In the present study, the midpoint of the curve was $4.70 \mathrm{~mm}$ from the end. The instruments tested had $\mathrm{D}_{0}=0.25 \mathrm{~mm}$ and tapered $0.03 \mathrm{~mm} / \mathrm{mm}$ (Reciproc) and $0.65 \mathrm{~mm} / \mathrm{mm}$ (WaveOne) at $\mathrm{D}_{4.70}$. The instrument 
diameter at $\mathrm{n}$ millimeters from the tip, $\mathrm{Dn}$, can be calculated using the equation $\mathrm{Dn}=\mathrm{D}_{0}+\mathrm{n}$ (Conicd.).

Because the tip of the instrument was coincident with the end of the canal during each test, the diameter of the instrument in the region of maximum deformation was $\mathrm{D}_{4.70}$ for the simulated canal. Therefore, for the WaveOne instrument, $\mathrm{D}_{4.70}=0.25+4.70(0.65)=3.305 \mathrm{~mm}$ and for the Reciproc instrument, $\mathrm{D}_{4.70}=0.391 \mathrm{~mm}$ initially.

Substituting these values into the equation $\varepsilon=(2 \mathrm{r} / \mathrm{d}-1)^{-1}$, where $\mathrm{r}=7.77 \mathrm{~mm}$ was the radius of the canal on the outside of the curve (taking into account that the internal diameter of the canal is $1.77 \mathrm{~mm}$ ), the maximum strain amplitudes ( $(\varepsilon)$ during the tests were $27.01 \%$ for the WaveOne instrument and $2.58 \%$ for the Reciproc instrument.

Although the deformation observed by those authors was established for the specific situation of continuous rotation, the concept was adopted in the present work even though reciprocating motion has a more complex dynamic. Despite additional strains being discounted because of the applied motion, there was an appreciable difference between the instruments, which may lead one to assume that this parameter could also have influenced the behavior of the WaveOne instrument.

Regarding the fracture characteristics that were found in the static and dynamic situations, scanning electron microscopy revealed that both the Reciproc and WaveOne instruments showed ductile fracture characteristics. A ductile fracture develops slowly as a crack propagates inside or on the edge of the material. A ductile fracture is the result of a severe plastic deformation along the crack. Considering these factors, one should take into account external variables, such as the type of load and the speed of its application, the temperature, and the state of the prevailing stresses. Additionally, changes in the geometry of the material lead to concentrations of points of stress, especially in cases of dynamic stress. ${ }^{22}$

From these data, it can be deduced that the geometry of the instrument complicates its resistance to static or dynamic cyclic fracture. Configurations with complex geometries can lead to critical situations during use.

Furthermore, the more complex the geometry, the more difficulties in analyzing the prevailing stresses in the instrument during its operation for both simple bench analyses and primarily mathematical models. Therefore, until these new methods and models are developed, it can be stated that instruments with simple cross-sectional designs constructed from current NiTi alloys, with stable tapering and without large variations along the working length, offer increased safety in the use of endodontic instruments in critical situations.

\section{Conclusions}

Given the above, the following conclusions may be drawn:

1. The Reciproc 25-08 instrument is more resistant to static and dynamic cyclic fracture than the WaveOne 25-08 instrument;

2. The WaveOne 25-08 instrument is less flexible than the Reciproc 25-08 instrument;

3. Given a specific alloy, the cross-section of the straight section of an instrument and its geometry influences both bending and resistance to cyclic fracture;

4. Both of the instruments tested had ductile fracture characteristics.

\section{Acknowledgments}

All the staff of the Laboratory of Applied Biotechnology (LABA) supported the construction of the equipment and the testing process. 


\section{References}

1. Walia HM, Brantley WA, Gerstein H. An initial investigation of the bending and torsional properties of nitinol root canal files. J Endod. 1988 Jul;14(7):346-51.

2. Peters OA. Current challenges and concepts in the preparation of root canal systems: a review. J Endod. 2004 Aug;30(8):559-67.

3. Gergi R, Rjeily JA, Sader J, Naaman A. Comparison of canal transportation and centering ability of twisted files, Pathfile-ProTaper system, and stainless steel hand K-files by using computed tomography. J Endod. 2010 May;36(5):904-7.

4. Ankrum MT, Hartwell GR, Truitt JE. K3 Endo, ProTaper, and ProFile systems: breakage and distortion in severely curved roots of molars. J Endod. 2004 Apr;30(4):234-7.

5. Parashos $\mathrm{P}$, Messer HH. Rotary NiTi instrument fracture and its consequences. J Endod. 2006 Nov;32(11):1031-43.

6. Gambarini G. Cyclic fatigue of nickel-titanium rotary instruments after clinical use with low- and high-torque endodontic motors. J Endod. 2001 Dec;27(12):772-4.

7. Varela-Patiño $P$, Ibañez-Párraga A, Rivas-Mundiña $B$, Cantatore G, Otero XL, Martin-Biedma B. Alternating versus continuous rotation: a comparative study of the effect on instrument life. J Endod. 2010 Jan;36(1):157-9.

8. Wan J, Rasimick BJ, Musikant BL, Deutsch AS. A comparison of cyclic fatigue resistance in reciprocating and rotary nickel-titanium instruments. Aust Endod J. 2011 Dec;37(3):122-7.

9. De-Deus G, Moreira EJ, Lopes HP, Elias CN. Extended cyclic fatigue life of F2 ProTaper instruments used in reciprocating movement. Int Endod J. 2010 Dec;43(12):1063-8.

10. You SY, Bae KS, Baek SH, Kum KY, Shon WJ, Lee W. Lifespan of one nickel-titanium rotary file with reciprocating motion in curved root canals. J Endod. 2010 Dec;36(12):1991-4.

11. Kim HC, Kwak SW, Cheung GS, Ko DH, Chung SM, Lee W. Cyclic fatigue and torsional resistance of two new nickel-titanium instruments used in reciprocation motion: Reciproc versus WaveOne. J Endod. 2012 Apr;38(4):541-4.

12. Lopes HP, Elias CN, Castro AMM, Fidel RAS, Moreira EJL. Flexibilidade de instrumentos endodônticos de NiTi acionados a motor. Rev Odontol Bras Cent. 2006 Jul-Dec;15(40):71-7.

13. Franco V, Fabiani C, Taschieri S, Malentacca A, Bortolin $\mathrm{M}$, Del Fabbro M. Investigation on the shaping ability of nickel-titanium files when used with a reciprocating motion. J Endod. 2011 Oct;37(10):1398-401.
14. Grande NM, Plotino G, Pecci R, Bedini R, Malagnino VA, Somma F. Cyclic fatigue resistance and three-dimensional analysis of instruments from two nickel-titanium rotary systems. Int Endod J. 2006 Oct;39(10):755-63.

15. Park SY, Cheung GS, Yum J, Hur B, Park JK, Kim HC. Dynamic torsional resistance of nickel-titanium rotary instruments. J Endod. 2010 Jul;36(7):1200-4.

16. Webber J, Machtou P, Pertot W, Kuttler S, Ruddle C, West J. The WaveOne single-file reciprocating system. Int Dent - African Ed. 2012 Jan-Feb;2(1):26-36.

17. Plotino G, Grande NM, Sorci E, Malagnino VA, Somma F. A comparison of cyclic fatigue between used and new Mtwo Ni-Ti rotary instruments. Int Endod J. 2006 Sep;39(9):716-23.

18. Plotino G, Grande NM, Testarelli L, Gambarini G. Cyclic fatigue of Reciproc and WaveOne reciprocating instruments. Int Endod J. 2012 Jul;45(7):614-8.

19. Ferreira MM, Rebelo D, Caramelo F, Carrilho E, Loureiro $M$. In vitro evaluation of wear and canal transportation using reciprocating instruments: RECIPROC ${ }^{\circledR}$ vs WaveOne ${ }^{\circledR}$ files. Rev Port Estomatol Cir Maxilofac. 2013 Jul-Sep;54(3):117-23.

20. De-Deus G, Vieira VTL, Silva EJN, Lopes H, Elias $\mathrm{CN}$, Moreira EJ. Bending resistance and dynamic and static cyclic fatigue life of Reciproc and WaveOne large instruments. J Endod. 2014 Apr;40(4):575-9.

21. Zhang EW, Cheung GS, Zheng YF. Influence of cross-sectional design and dimension on mechanical behavior of nickel-titanium instruments under torsion and bending: a numerical analysis. J Endod. 2010 Aug;36(8):1394-8.

22. Hibbeler R. Resistência dos materiais [Resistance of materials]. 7th ed. São Paulo: Pearson Education do Brasil; Plotino G, Grande NM, Cordaro M, Testarelli L, Gambarini G. A review of cyclic fatigue testing of nickel-titanium rotary instruments. J Endod. 2009 Nov;35(11):1469-76.

23. Shen Y, Cheung GSP. Methods and models to study nickel-titanium instruments. Endod Topics. 2013 Sep;29(1):18-41.

24. Tsao CC, Liou JU, Wen PH, Peng CC, Liu TS. Study on bending behaviour of nickel-titanium rotary endodontic instruments by analytical and numerical analyses. Int Endod J. 2013 Apr;46(4):379-88.

25. Bahia MGA, Dias RF, Buono VTL. The influence of high amplitude cyclic straining on the behaviour of superelastic NiTi. Int J Fatigue. 2006 Sep; 29(1):1087-91. 